\title{
Formation of microbeads during vapor explosions of Field's metal in water
}

\author{
N. Kouraytem, E. Q. Li, and S. T. Thoroddsen \\ Division of Physical Sciences and Engineering, King Abdullah University of Science and Technology (KAUST), \\ Thuwal 23955-6900, Saudi Arabia \\ (Received 17 April 2016; published 17 June 2016)
}

\begin{abstract}
We use high-speed video imaging to investigate vapor explosions during the impact of a molten Field's metal drop onto a pool of water. These explosions occur for temperatures above the Leidenfrost temperature and are observed to occur in up to three stages as the metal temperature is increased, with each explosion being more powerful that the preceding one. The Field's metal drop breaks up into numerous microbeads with an exponential size distribution, in contrast to tin droplets where the vapor explosion deforms the metal to form porous solid structures. We compare the characteristic bead size to the wavelength of the fastest growing mode of the Rayleigh-Taylor instability.
\end{abstract}

DOI: 10.1103/PhysRevE.93.063108

\section{INTRODUCTION}

When molten metal comes in contact with water, nucleate or film boiling rapidly sets in. Under some conditions the vapor layer separating the two liquids becomes unstable and a more violent interaction takes place. This phenomenon is known as a thermal or vapor explosion and is relevant to many natural and practical fields, including fuel coolant interaction in nuclear power plants [1-7] and contact between ejected lava with sea water or ice [8-15]. Herein we model such interactions with the impact of a molten metal droplet falling onto a water pool, where the metal temperature is far above the boiling temperature of water. As the molten metal meets the pool liquid, we observe nucleate boiling, i.e., the rapid growth and collapse of bubbles around the drop's surface. Or, when the temperature of the metal is above the Leidenfrost temperature of the system [16-19], a vapor layer forms around the molten metal, eliminating direct contact with the water, which greatly reduces the heat transfer. The break-up of this layer allows vapor and liquid to penetrate into the molten metal and the water boils in a rapid thousand-fold expansion producing a vapor explosion [20-23]. Such explosions become more violent at higher metal temperatures [24-30].

In this communication, we show that the vapor explosion of molten Field's metal in water produces a multitude of microbeads, while for tin the debris is characterized by a porous solid network. A vapor explosion, in the former case, could potentially be a low-cost technique of generating such microbeads.

\section{EXPERIMENTAL SETUP}

The high-speed imaging is accomplished with a Photron SA5 or a Phantom V710 high-speed video camera at frame rates up to $50000 \mathrm{fps}$. A pair of $350 \mathrm{~W}$ metal-halide light sources (Sumita Optical Glass) equipped with fiber-optic light guides were used to provide back- and front-lighting. As depicted in Fig. 1, the front light source provided lighting for reflective imaging of the metal and free surfaces. These light sources induced minimal heating of the water, as checked with a thermometer. We used a Nikon $105 \mathrm{~mm}$ lens to achieve up to $58 \mu \mathrm{m} / \mathrm{px}$ resolution. All experiments were conducted in the laboratory's controlled environment where the relative humidity is $55 \%$ and the temperature is $22{ }^{\circ} \mathrm{C}$.

The molten metal drops consist of either tin or Field's metal, whose properties are given in Table I. These two metals were selected due to their greatly different melting temperatures. Field's metal is an eutectic alloy that is known for its very low melting point of $60^{\circ} \mathrm{C}$, whereas tin melts at $230^{\circ} \mathrm{C}$. The value of the surface tension $\sigma$ for Field's metal was not readily available but can be roughly estimated from the properties of the main components [31]. Using a bimodal bismuth $(\sigma \sim 0.37 \mathrm{~N} / \mathrm{m})$ and indium $(\sigma \sim 0.58 \mathrm{~N} / \mathrm{m})$ alloy would give $\sigma_{\text {Fields }} \sim 0.4 \mathrm{~N} / \mathrm{m}$ at $\sim 250{ }^{\circ} \mathrm{C}[32,33]$. To support this approximate value we do our own estimate with the pendent drop technique [34], as shown in Fig. 2. Here we observe the pinch-off of the drop inside an oven through a glass door. A few drops were released in rapid succession to minimize oxide formation on the surface. This gives $\sigma \simeq 0.41 \mathrm{~N} / \mathrm{m}$ for Field's metal at $108^{\circ} \mathrm{C}$.

A small amount of the solid metal $(\simeq 5 \mathrm{~g})$ is placed in a crucible and melted in a high-temperature furnace. The molten metal drops are heated to temperatures between 250 and $550{ }^{\circ} \mathrm{C}$ before they are dropped in a pool of deionized water at room temperature. The inner dimensions of the glass container are $10 \times 10 \mathrm{~cm}$ in cross section and $15 \mathrm{~cm}$ depth. Post-heating, the molten metal is placed inside the crucible and transferred to the setup where it is clamped right above the center of the liquid pool, before the drop is manually released by tipping over the crucible. The drops free fall for $\sim 10 \mathrm{~cm}$, to reach an impact velocity of $U \simeq 1.4 \mathrm{~m} / \mathrm{s}$ when they hit the pool surface. This method generates larger droplets than is possible by simple pinch-off from a nozzle. The bottom radius of curvature of the metal is about $4 \mathrm{~mm}$. Each trial is recorded with the high-speed video camera. The container is then cleaned of the debris for analysis, and it is filled again with pure water for the next trial.

The metal loses a minimal amount of heat, between the removal from the furnace, until the impact. We ignore the heat loss while the metal sits for a few seconds inside the crucible, whereas we use empirical relations to estimate the heat loss during the free fall through the air. The temperature is constant throughout the inside of the metal droplet, as the Biot number, $\mathrm{Bi}=h L_{c} / k$ is in the order of $10^{-4}$. Here $h$ is the heat transfer coefficient for air, $L_{c}$ is the characteristic length, which for 


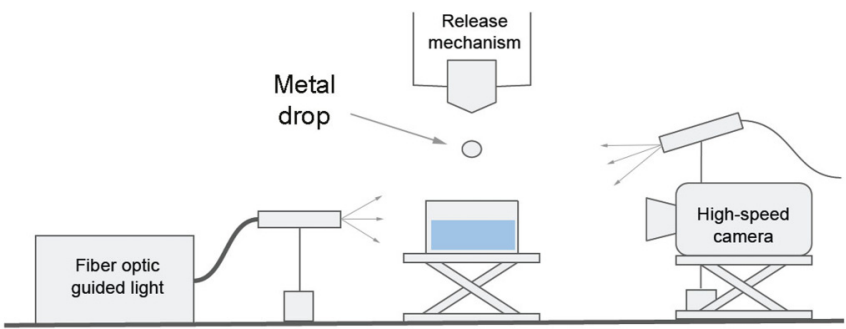

FIG. 1. Schematic showing the experimental setup.

a sphere is a fraction of its diameter $D / 6$, and $k$ the thermal conductivity of the metal. For the laminar Reynolds number $\operatorname{Re}=\rho U D / \mu \approx 725$ and the Prandtl number of the air is $\operatorname{Pr}=0.71$, empirically the Nusselt number can be estimated as [35]

$$
\mathrm{Nu}=2+\left(0.4 \operatorname{Re}^{1 / 2}+0.06 \operatorname{Re}^{2 / 3}\right) \operatorname{Pr}^{0.4}\left(\mu_{\infty} / \mu_{s}\right)^{1 / 4},
$$

giving a value of about 14 . The thermal boundary layer is calculated by the approximation $\delta_{t}=(\alpha D / U)^{1 / 2}$ where $\alpha$ is the thermal diffusivity of air, hence $\delta_{t} \sim 220 \mu \mathrm{m}$. The cooling of the droplet can then be computed using the lumped capacitance method giving a temperature loss between 1 and $4{ }^{\circ} \mathrm{C}$, with the larger number for the highest droplet temperature.

To study the metal debris, we extract it from the bottom of the water tank, dry it, and suspend in glycerin. This allows us to form an even suspension of the different sized beads within a viscous liquid bath. Subsequently, a 10\% sample is extracted, and all solid metal beads within are manually measured under a microscope, with $\sim 1000$ beads per experiment.

The Leidenfrost temperature $T_{L}$ is usually determined by slowly depositing a liquid drop on the surface of a hotplate. Here we are dealing with the metal-water system, so it is more natural to use a metal pool and deposit a water drop to determine this. For tin this has been done by Miyazaki et al. [26] and they find $T_{L}=195^{\circ} \mathrm{C}$, which corresponds to the tin still being solid. We have now conducted the same experiment with the Field's metal, which is now fully molten, and we find the Leidenfrost transition occurs at $T_{L} \simeq 210^{\circ} \mathrm{C}$. It is not trivial to connect this information to the dynamics of the impacting case studied herein, as the vapor explosions are basically unstable Leidenfrost vapor layers and always occur for drops above this transition temperature.

TABLE I. Properties of the tin alloy and Field's metal [39] used in the experiments.

\begin{tabular}{lcc}
\hline \hline & Field's metal & Tin \\
\hline Composition & Indium $(51 \%)$ & $99.95 \% \mathrm{Sn}$ \\
& Bismuth $(32.5 \%)$ & Surepure \\
& Tin $(16.5 \%)$ & Chemetals, Inc. \\
Melting temperature, $T$ & $60^{\circ} \mathrm{C}$ & $230^{\circ} \mathrm{C}$ \\
Density, $\rho$ & $6740 \mathrm{~kg} / \mathrm{m}^{3}$ & $7280 \mathrm{~kg} / \mathrm{m}^{3}$ \\
Specific heat, $c$ & $184 \mathrm{~J} / \mathrm{kg} \cdot \mathrm{K}$ & $210 \mathrm{~J} / \mathrm{kg} \cdot \mathrm{K}$ \\
Thermal conductivity, $\kappa$ & $10 \mathrm{~W} / \mathrm{m} \cdot \mathrm{K}$ & $66.8 \mathrm{~W} / \mathrm{m} \cdot \mathrm{K}$ \\
Surface tension, $\sigma$ & $0.41 \mathrm{~N} / \mathrm{m}$ & $0.54 \mathrm{~N} / \mathrm{m}$ \\
\hline \hline
\end{tabular}

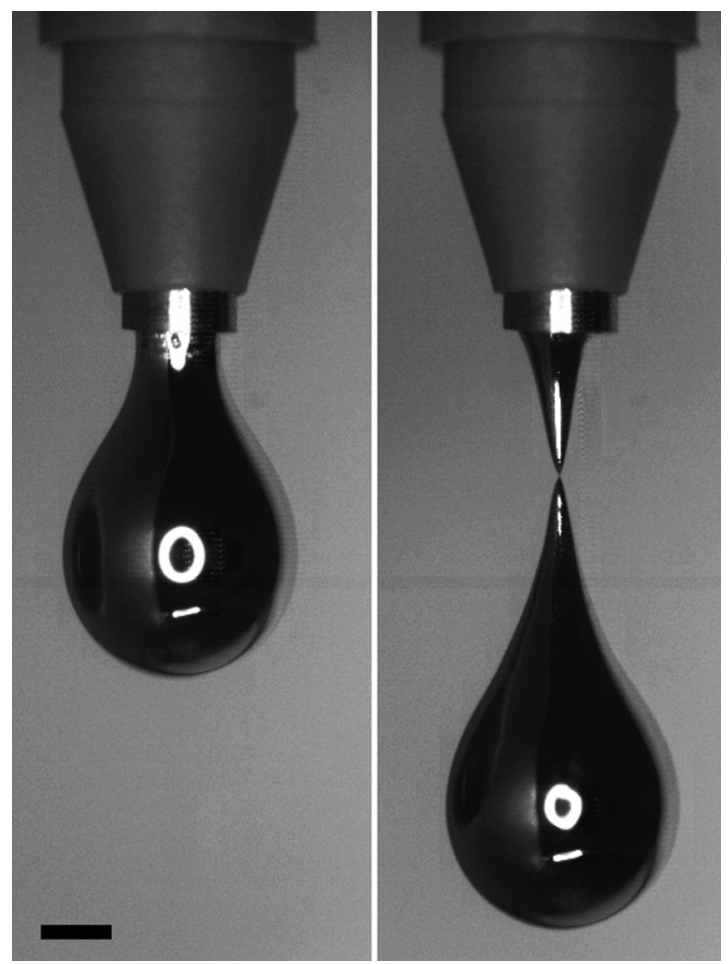

FIG. 2. Images used for determining the surface tension of Field's metal, using the pendent drop method. Left shows the start of the fall, with near-vertical sides and the right side the pinch-off instant $56 \mathrm{~ms}$ later. The scale bar is $1 \mathrm{~mm}$ long.

\section{RESULTS}

The interaction between the molten metal drop and the water exhibits one of two potential responses, either nucleate boiling [Fig. 3(a)] or film boiling followed by vapor explosion [Figs. 3(b) and 4]. Impact experiments were performed to pinpoint the transition between these two behaviors for two metals: tin and Field's metal and to study their debris structure (Figs. 5 and 6). The temperature of the molten metal was
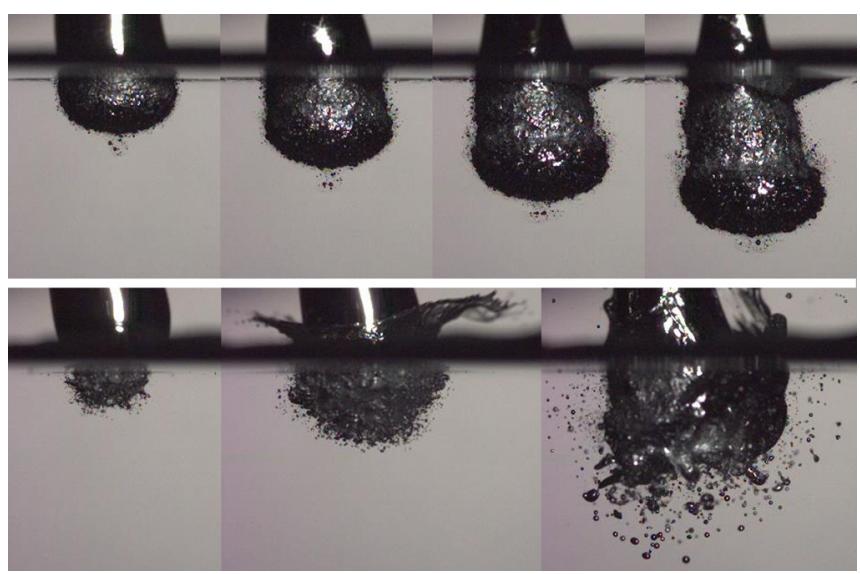

FIG. 3. Comparison between nucleate boiling for a $350{ }^{\circ} \mathrm{C}$ Field's metal drop (top) and vapor explosion for a $400^{\circ} \mathrm{C}$ Field's metal drop (bottom), falling into a pool of water. See also Supplemental Videos SV2 and SV3 [36]. 

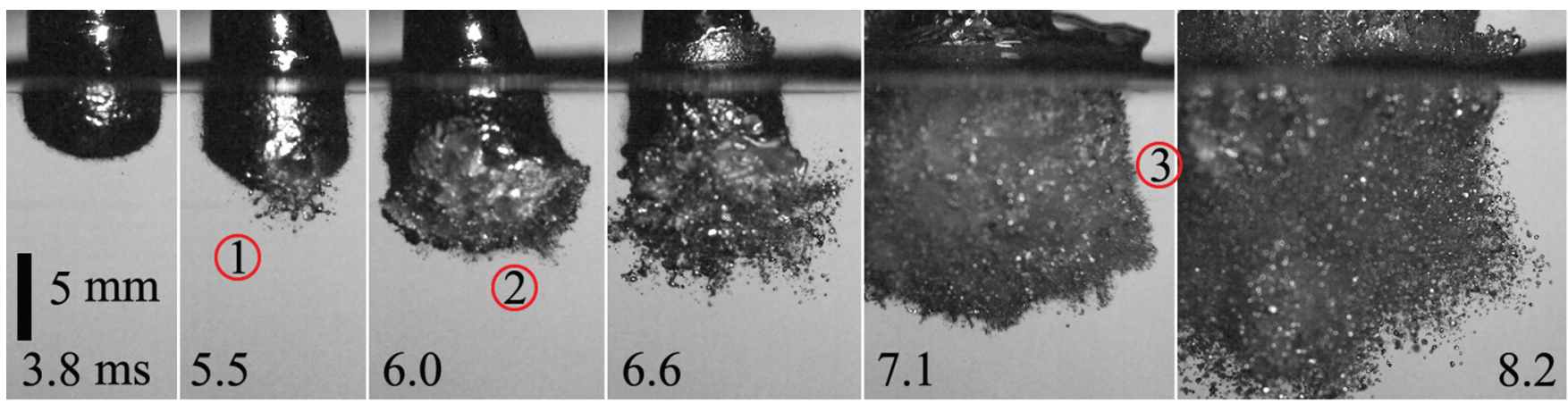

FIG. 4. Vapor explosion of a $550^{\circ} \mathrm{C}$ Field's metal drop falling into $22^{\circ} \mathrm{C}$ deionized water. See also Supplemental Video SV6 [36]. The circled numbers indicate the different vapor explosions.

changed in steps of 25 or $50^{\circ} \mathrm{C}$ in order to determine this transition. Figure 7 identifies the limits between the two regimes for both metals. While the tin transitions from nucleate boiling to vapor explosions at $350^{\circ} \mathrm{C}$, Field's metal vapor explosions are observed only at a higher temperature of $400{ }^{\circ} \mathrm{C}$.

For the case of nucleate boiling, we observe pulsation of the water vapor around the molten tin drop at a rate of $4000 \mathrm{~Hz}$, see Supplemental Video SV1 [36]. In that case the molten metal drop does not exhibit vapor explosion but rather has a densely packed layer of vapor bubbles that form and collapse at the interface. However, for the vapor explosion case, more complex dynamics are observed.

Figure 4 shows the sequence of events in detail for Field's metal. Looking closely at the dynamics of the vapor explosion, the high-speed videos show that the molten metal drop enters the water pool in a film boiling state where the metal is surrounded by a vapor layer and penetrates for about $5 \mathrm{~ms}$ before the vapor explosion begins. However, the explosion occurs in stages. The first explosion is localized and weak. Following this, the expanded vapor volume around the molten

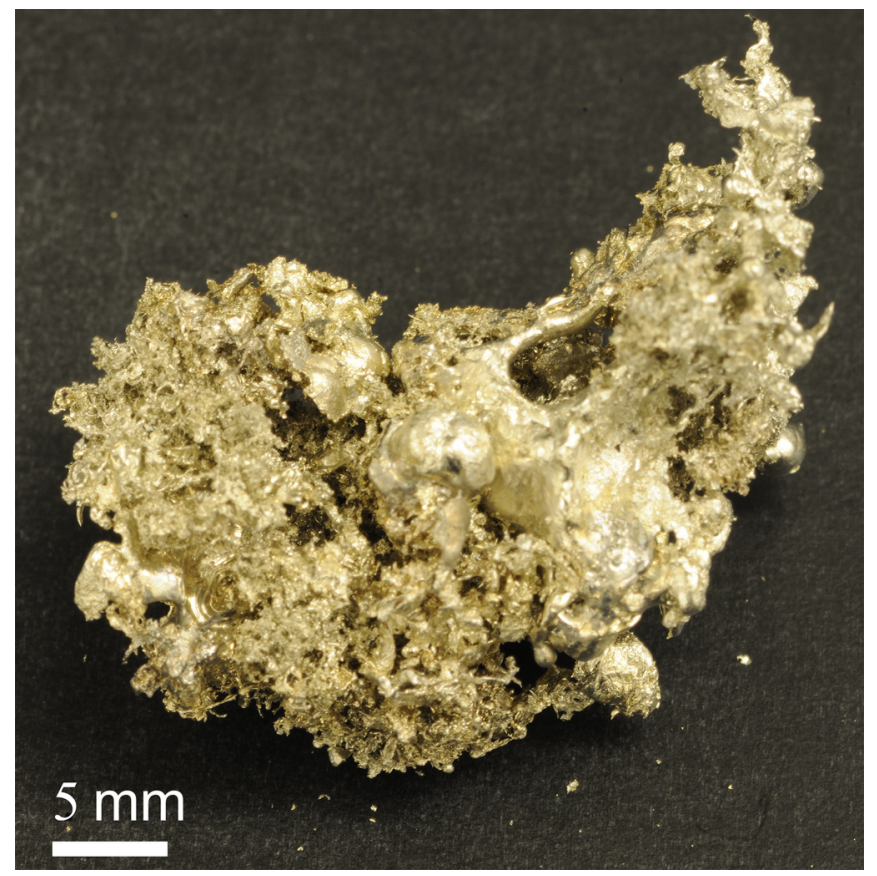

FIG. 5. Porous debris resulting from the vapor explosion of tin. metal rapidly retracts, pauses, and explodes a second time (marked as 2 in Fig. 4). Finally a third and most powerful explosion is observed in this case of the highest metal temperature (number 3 in Fig. 4). During each explosion, the surface layer of the metal drop is split into small beads, which are ejected into the pool. The collapse of the vapor pocket between explosions may be from rapid condensation on the vapor-liquid interface. As more water gets entrapped near the superhot metal, it heats up rapidly and vaporizes while increasing its volume by at least 1000 times creating a second explosion. The dynamics of these stages are clearly very complex, but below we propose a simplified hydrodynamic instability. As the drop temperature is increased the explosions become more violent, as is evident in the Supplemental Videos SV3-SV6 [36] for Field's metal at $400-550^{\circ} \mathrm{C}$. The remainder of the drop falls into the liquid pool as it solidifies. Note that all of our experiments are self-triggered, whereas, in some other configurations, a gas trigger [3] or a shock wave [15] are applied to destabilize the vapor layer.

\section{A. Rayleigh-Taylor instability}

The expansion of the vapor layer around the molten drop is rapid, and one can speculate that Rayleigh-Taylor instability destabilizes the free surfaces, especially at the vapor-water interface, which is unstable to this direction of acceleration. We measure the acceleration of this interface from the high-speed video frames, seeing maximum velocities $u \simeq 20 \mathrm{~m} / \mathrm{s}$ and accelerations as high as $a \simeq 200000 \mathrm{~m} / \mathrm{s}^{2}$.The fastest growing

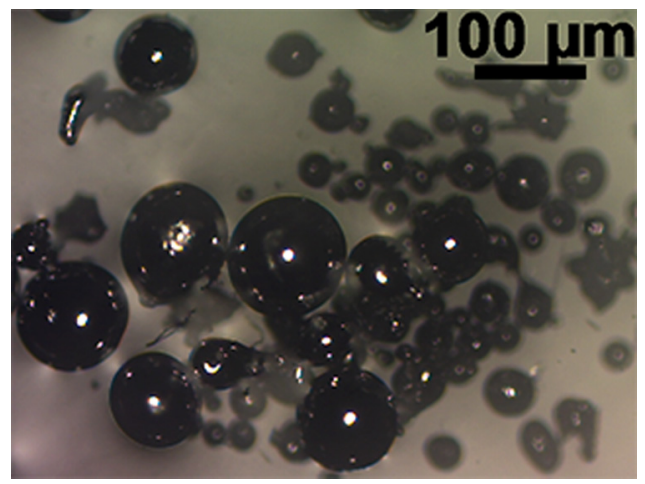

FIG. 6. Solidified debris resulting from the vapor explosion of Field's metal. 


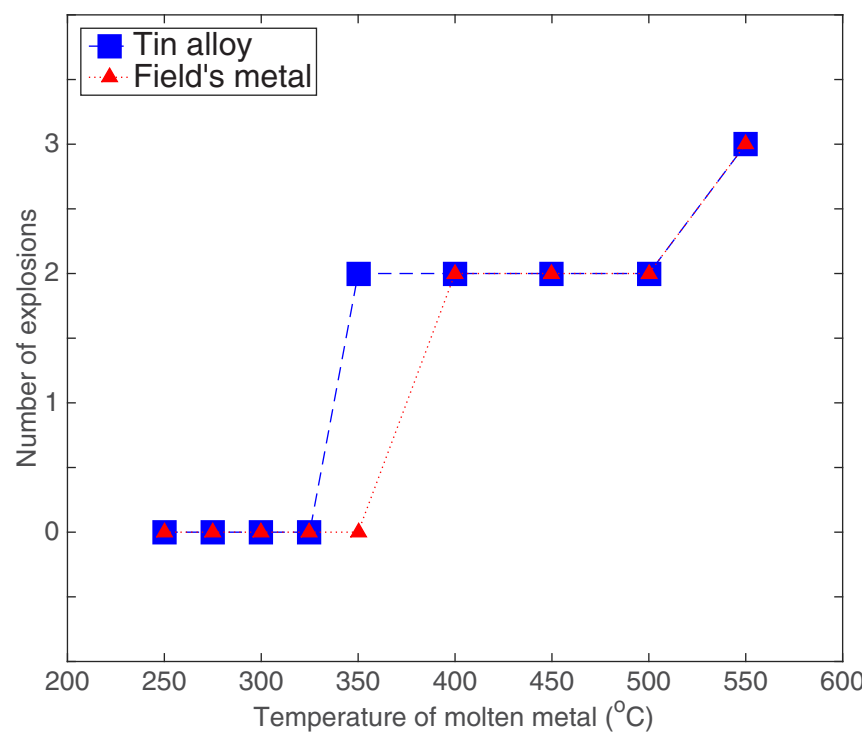

FIG. 7. Transition temperature of tin and Field's metal droplets from nucleate boiling to vapor explosions while impacting a pool of deionized water.

wave number $k^{*}$ of this instability is then given by [37]

$$
k^{*}=\sqrt{\frac{a \times\left(\rho_{\mathrm{liq}}-\rho_{\mathrm{vap}}\right)}{\sigma},},
$$

where $\rho_{\text {liq }}$ and $\rho_{\text {vap }}$ are the densities of the water and its vapor, while $\sigma$ is the surface tension of water. For the third explosion in Fig. $4, k_{*}=67000 \mathrm{~m}^{-1}$ and $\lambda^{*}=2 \pi / k^{*} \simeq 94 \mu \mathrm{m}$.

This simple estimate is consistent with the characteristic bead size for the Field's metal (Fig. 9). Figure 8 shows the corresponding wavelengths $\lambda^{*}$ as function of the metal temperature and the number of the explosion. The reduction in the $\lambda^{*}$ values shows the increased strength of each subsequent explosion. Following the vapor explosions, the molten tin

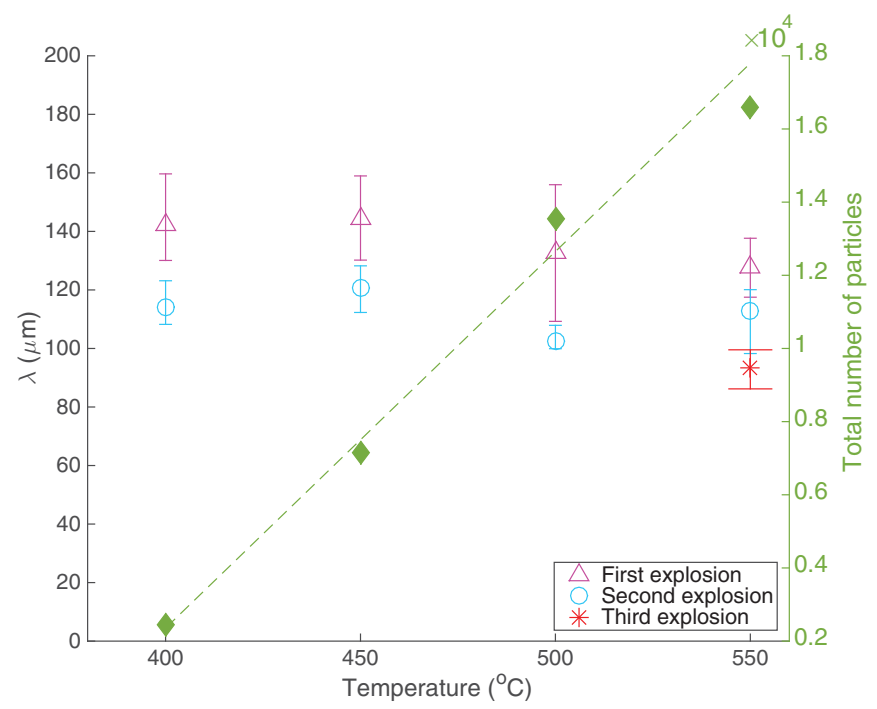

FIG. 8. Most unstable Rayleigh-Taylor wavelength on the watervapor interface from Eq. (1), as a function of the temperature of the Field's metal. Determined with accelerations from videos such as in [36]. The right axis shows the total number of beads produced in each explosion.
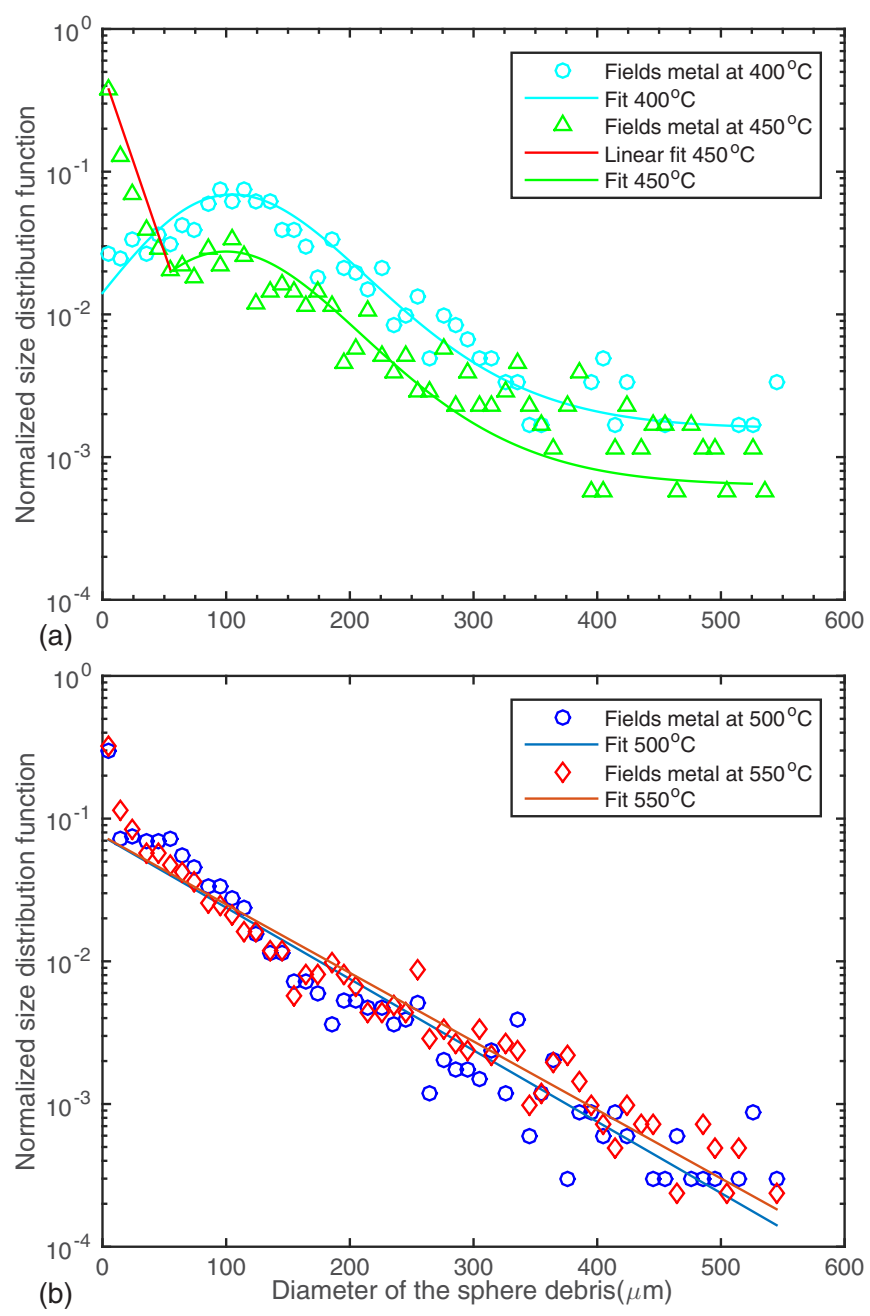

FIG. 9. The normalized size distribution of the diameter of the spherical Field's metal debris, following vapor explosion in water, for different metal temperatures. (a) Field's metal at 400 and $450{ }^{\circ} \mathrm{C}$; (b) Field's metal at 500 and $550{ }^{\circ} \mathrm{C}$. Solid lines represent fit for exponential distributions.

forms a porous solid structure (Fig. 5), whereas a Field's metal produces detached beads of metal from the drop [Figs. 3(b) and 6] whose sizes we now characterize. The beads are spherical in shape as seen under the microscope (Fig. 6). Following each vapor explosion, the debris detaching from the Field's metal drops were collected and dried. Keep in mind that not all of the metal drop transforms into beads, but a large central piece solidifies. The bead size distribution was characterized under the microscope for all the cases where vapor explosion occurred, namely $400-550^{\circ} \mathrm{C}$.

\section{B. Bead size distribution}

It is clear from this imaging that the sizes of the beads are not constant. Depending on the temperature of the molten metal, the number of beads resulting from the explosion as well as their size vary. They fall in a range of sizes from about 7 to $550 \mu \mathrm{m}$ diameter. The total number of beads increases 
approximately linearly with the metal-drop temperature, as shown in Fig. 8, to reach about 16000 microbeads in the $550{ }^{\circ} \mathrm{C}$ case. The relative number fraction of the smallest microbeads also increases with increasing temperature.

Figure 9 shows the normalized probability density function (pdf) of the sizes of the beads produced at different metal temperatures. The pdf is normalized based on the number of beads in the particular size range, compared to the total number. At $400{ }^{\circ} \mathrm{C}$, i.e., the lowest explosion temperature, the size distribution has a characteristic peak at $d \sim$ $110 \mu \mathrm{m}$. At $450^{\circ} \mathrm{C}$, the pdf shows a composite character with a local peak at $d \sim 100 \mu \mathrm{m}$, but an exponential part at smaller diameters. For the highest metal temperatures of 500 and $550{ }^{\circ} \mathrm{C}$, on the other hand, the size distribution exhibits a pure exponential shape in both cases. Hence as the temperature increases, the size pdf shifts from one with a localized peak to an exponential one, $p(d) \sim \exp \left(-d / d_{r}\right)$, where $d_{r}$ is a characteristic size, which here takes the value of $200 \mu \mathrm{m}$. Similar size distributions arise during the breakup of drops impacting on a solid surface as described by $\mathrm{Xu}$ et al. [38]. The underlying physical reason for this distribution is not clear. The nature of the breakup process will certainly introduce a cutoff for $d_{\min }$. Here we speculate that the metal surface tension will prevent additional break-up, when the Weber number $\rho d_{\min } u^{2} / \sigma \sim 1$, hence (estimating $\sigma \sim 0.4 \mathrm{~N} / \mathrm{m}) d_{\min } \sim 0.2 \mu \mathrm{m}$, which is below the resolution of our high-speed imaging.

\section{CONCLUSIONS}

We have shown that vapor explosions by molten Field's metal in water produce a multitude of spherical microbeads, while molten tin leaves behind a continuous porous solid structure. We propose the underlying reason for this difference in the debris is the much lower melting point of the Field's metal $\left(60^{\circ} \mathrm{C}\right)$ than that of the tin $\left(230^{\circ} \mathrm{C}\right)$. This allows the molten metal to break up into small droplets before it solidifies. Tin may therefore break up into beads if it starts out at much higher temperatures, as suggested by Dullforce et al. [24]. The nature of the debris size distribution changes from one with a local peak, to an exponential one, when the metal temperature becomes higher, which increases the number and strength of the vapor explosions.

\section{ACKNOWLEDGMENTS}

The research described herein was funded by KAUST. We acknowledge financial support from CCRC at KAUST, Extreme Combustion FCC/1/1975. We thank Ivan Vakarelski for help with some of the experiments.
[1] S. J. Board, R. W. Hall, and R. S. Hall, Detonation of fuel coolant explosions, Nature (London) 254, 319 (1975).

[2] A. Ciampichetti, D. Pellini, P. Agostini, G. Benamati, N. Forgione, and F. Oriolo, Experimental and computational investigation of LBE-water interaction in LIFUS 5 facility, Nucl. Eng. Des. 239, 2468 (2009).

[3] I. Huhtiniemi and D. Magallon, Insight into steam explosions with corium melts in KROTOS, Nucl. Eng. Des. 204, 391 (2001).

[4] A. Inoue, K. Takahashi, M. Takahashi, and M. Matsuzaki, Transient film boiling under transient conditions related to vapor explosion (effects of transient flow and fragmentation under a shock pressure), Nucl. Eng. Des. 155, 55 (1995).

[5] R. Meignen, B. Raverdy, M. Buck, G. Pohlner, P. Kudinov, W. Ma, C. Brayer, P. Piluso, S. Hong, M. Leskovar, M. Ursic, G. Albrecht, I. Lindholm, and I. Ivanov, Status of steam explosion understanding and modeling, Ann. Nucl. Energy 74, 125 (2014).

[6] R. Meignen, B. Raverdy, S. Picchi, and J. Lamome, The challenge of modeling fuel-coolant interaction: Part II-Steam explosion, Nucl. Eng. Des. 280, 528 (2014).

[7] S. Wang, M. Flad, W. Maschek, P. Agostini, D. Pellini, G. Bandini, T. Suzuki, and K. Morita, Evaluation of a steam generator tube rupture accident in an accelerator driven system with lead cooling, Prog. Nucl. Energ. 50, 363 (2008).

[8] S. A. Colgate and T. Sigurgeirsson, Dynamic mixing of water and lava, Nature (London) 244, 552 (1973).

[9] C. I. Schipper, J. D. L. White, B. Zimanowski, R. Bttner, I. Sonder, and A. Schmid, Experimental interaction of magma and "dirty" coolants, Earth Planet. Sci. Lett. 303, 323 (2011).

[10] J. D. L. White, Impure coolants and interaction dynamics of phreatomagmatic eruptions, J. Volcanol. Geoth. Res. 74, 155 (1996).
[11] K. H. Wohletz, Water/magma interaction: Physical considerations for the deep submarine environment, Explosive Subaqueous Volcanism (American Geophysical Union Monograph, Washington, DC, 2003), p. 25.

[12] K. H. Wohletz, Water/magma interaction: Some theory and experiments on peperite formation, J. Volcanol. Geoth. Res. 114, 19 (2002).

[13] K. H. Wohletz, Explosive magma-water interactions: Thermodynamics, explosion mechanisms, and field studies, Bull. Volcanol. 48, 245 (1986).

[14] B. Zimanowski and R. Büttner, Phreatomagmatic explosions in subaqueous volcanism, Explosive Subaqueous Volcanism (American Geophysical Union Monograph, Washington, DC, 2003), p. 51.

[15] B. Zimanowski, R. Buttner, V. Lorenz, and H. S. Hafele, Fragmentation of basaltic melt in the course of explosive volcanism, J. Geophys. Res.-Sol. Ea. 102, 803 (1997).

[16] A. Biance, C. Clanet, and D. Quéré, Leidenfrost drops, Phys. Fluids 15, 1632 (2003).

[17] D. Quéré, Leidenfrost dynamics, Annu. Rev. Fluid Mech. 45, 197 (2013).

[18] I. U. Vakarelski, J. O. Marston, D. Y. C. Chan, and S. T. Thoroddsen, Drag reduction by Leidenfrost vapor layers, Phys. Rev. Lett. 106, 214501 (2011).

[19] J. O. Marston, I. U. Vakarelski, and S. T. Thoroddsen, Cavity formation by the impact of Leidenfrost spheres, J. Fluid. Mech. 699, 465 (2012).

[20] G. Ciccarelli and D. L. Frost, Fragmentation mechanisms based on single drop steam explosion experiments using flash $\mathrm{x}$-ray radiography, Nucl. Eng. Des. 146, 109 (1994). 
[21] M. L. Corradini, B. J. Kim, and M. D. Oh, Vapor explosions in light water reactors: A review of theory and modeling, Prog. Nucl. Energ. 22, 1 (1988).

[22] D. F. Fletcher and R. P. Anderson, A review of pressure-induced propagation models of the vapour explosion process, Prog. Nucl. Energ. 23, 137 (1990).

[23] L. S. Nelson, P. W. Brooks, R. Bonazza, M. L. Corradini, K. Hildal, and T. H. Bergstrom, Steam explosions of single drops of molten silicon-rich alloys, in Proceedings of the Ninth International Ferroalloys Congress (INFACON 9) (Ferroalloys Association, Washington, DC, 2005), pp. 338-351.

[24] T. A. Dullforce, D. J. Buchanan, and R. S. Peckover, Selftriggering of small-scale fuel-coolant interactions: I. Experiments, J. Phys. D: Appl. Phys. 9, 1295 (1976).

[25] K. Matsumura and H. Nariai, Self-triggering mechanism of vapor explosions for a molten tin and water system, J. Nucl. Sci. Technol. 33, 298 (1996).

[26] K. Miyazaki, K. Morimoto, O. Yamamoto, Y. Harada, and N. Yamaoka, Thermal interaction of water droplet with molten tin, J. Nucl. Sci. Technol. 21, 907 (1984).

[27] M. Lin, Y. Zhou, M. Zhong, X. Yan, and Y. Yang, Molten metal and water direct contact interaction research II. Numerical analysis, Ann. Nucl. Energ. 70, 256 (2014).

[28] R. Sa, M. Takashashi, and K. Moriyama, Study on fragmentation behavior of liquid lead alloy droplet in water, Prog. Nucl. Energ. 53, 895 (2011).

[29] R. P. Taleyarkhan, Preventing melt-water explosions, JOM 50, 35 (1998).
[30] S. M. Zielinski, A. A. Sansone, M. Ziolkowski, and R. P. Taleyarkhan, Prevention and intensification of melt-water explosive interactions, J. Heat Tranf. 133, 071201 (2011).

[31] K. S. Yeum, R. Speiser, and D. R. Poirier, Estimation of the surface tensions of binary liquid alloys, Metall. Trans. B 20, 693 (1989).

[32] D. W. G. White, The surface tensions of indium and cadmium, Metall. Trans. 3, 1933 (1972).

[33] B. B. Alchagirov and A. G. Mozgovoi, Experimental Investigation of the surface tension of liquid lead and bismuth in the vicinity of the melting point, High Temp. 41, 412 (2003).

[34] J. D. Berry, M. J. Neeson, R. R. Dagastine, D. Y. C. Chan, and R. F. Tabor, Measurement of surface and interfacial tension using pendant drop tensiometry, J. Colloid. Interface Sci. 454, 226 (2015).

[35] S. Whitaker, Forced convection heat transfer correlations for flow in pipes, past flat plates, single cylinders, single spheres, and for flow in packed beds and tube bundles, AIChE J. 18, 361 (1972).

[36] See Supplemental Material at http://link.aps.org/supplemental/ 10.1103/PhysRevE.93.063108 for videos of vapor explosions.

[37] S. Chandrasekhar, Hydrodynamic and Hydromagnetic Stability (Dover, New York, 1961).

[38] L. Xu, L. Barcos, and S. R. Nagel, Splashing of liquids: Interplay of surface roughness with surrounding gas, Phys. Rev. E 76, 066311 (2007).

[39] K. Shaikh, Design and development of a portable microfluidic system for medical diagnostics, Ph.D. dissertation, University of Illinois at Urbana-Champaign, 2007. 